Ambient Science, 2019: Vol. 06(2); 07-10

DOI:10.21276/ambi.2019.06.2.ra01

ambient

SCIENCE

Vol. 06(2):07-10

Year 2019

\title{
Molecular Analyses of the Prevalence of Campylobacter Detected from the Poultry Meat and its Byproducts
}

\section{Reyhaneh Rouhi Jahromi, Farhad Moradi, Saeedeh Erfanian, Seyyed Zabiholah Faraji, Mohsen Farhang Zargar, Bahareh Razeghi Haghighi, Masihollah Shakeri, Heshmatollah Shakeri, Abdolreza Sotoodeh Jahromi*}

Zoonoses Research Center, Jahrom University of Medical Sciences, Jahrom, Iran

Study Area: Jahrom, Iran

Coordinates: $28^{\circ} 30^{\prime} \mathrm{oo}^{\prime \prime} \mathrm{N} ; 53^{\circ} 33^{\prime} 38^{\prime \prime} \mathrm{E}$

Key words: Campylobacter jejuni, Campylobacter coli, Southwest of Iran

\section{Abstract}

Campylobacter is one of the most common bacteria that is usually transmitted between humans and animals. Among the animal source foods (ASF), the presence of the Campylobacter spp. in poultry meat has been extensively reported, while the consumption of undercooked meat is the most important means of transmission of this bacterium to humans. Hence, determining the prevalence of C.jejuni and C.coli in poultry meat and byproducts through the bacteriological and molecular methods was the pivot of this research. This descriptive cross-sectional study was conducted on poultry carcasses collected from the slaughterhouses of Jahrom-Iran. The presence of Campylobacter spp. in the samples was checked through bacteriological and molecular methods. Obtained data were analyzed by SPSS-16 on the descriptive statistics level. In the bacteriological examination, $0.91 \%$ and $3.98 \%$ of the samples were found to be infected with C.jejuni and other Campylobacter spp., respectively. In the molecular examination, $9.8 \%, 1.2 \%$, and $0.9 \%$ of the samples were found to be infected with C.coli, C.jejuni, and other Campylobacter spp., respectively. Thus, it was concluded that the prevalence of the Campylobacter species in poultry meat, Jahrom is lower than their prevalence in the poultry meat in other cities of Iran and other countries.

complications and acute paralysis (Vandeplas et al., 2008; Vicente et al., 2008). Campylobacteriosis is substantially important in humans, especially those who consume undercooked or raw poultry and cow meat. Campylobacter spp. have a greater pathogenic potential in children, old age people, and patients suffering from immuno-deficiency (Grennan et al., 2001). Thus, it is become necessary to study and identify the causes of contamination with Campylobacter in slaughterhouses due to increasing pathogenesis of this bacterium. Studying the prevalence of the Campylobacter spp. in poultry meat and byproducts in the slaughterhouses of Jahrom-Iran through bacteriological and molecular methods was the overarching goal of this research.

\section{Materials and methods:}

In this descriptive cross-sectional study, 328 samples of poultry carcasses were randomly collected from the slaughterhouses in Jahrom- Iran, Jan.2017-Jun.2017. Each sample was washed with $400 \mathrm{ml}$ of $0.1 \%$ sterilized peptone 
water, and the solution resulting from this process was filtered using a clean porous sterilized cloth and then was centrifuged for 30 minutes at $6000 x g$ at $42^{\circ} \mathrm{C}$. After throwing out the liquid on the surface, the sediment was cultured in $5 \mathrm{ml}$ of the Exeter broth enrichment medium containing; Cefoperazone $1.5 \mathrm{mg} /$ Lit, Amphotericin B 2 $\mathrm{mg} /$ Lit, Trimethoprim $10 \mathrm{mg} / \mathrm{Lit}$, Rifampin $5 \mathrm{mg} / \mathrm{Lit}$, and Polymyxin $2500 \mathrm{IU} / \mathrm{Lit}$. Following $48 \mathrm{hr}$ of microaerophilic incubation $\left(5 \% \mathrm{O}_{2}, 10 \% \mathrm{CO}_{2}, 85 \% \mathrm{~N}_{2}, 42^{\circ} \mathrm{C}\right)$, $0.1 \mathrm{ml}$ of the cultured sample in the enriched medium was isolated and cultured on a selective Skirrow Agar containing vancomycin $10 \mathrm{mg} / \mathrm{Lit}$, polymyxin B $250 \mathrm{mg} / \mathrm{Lit}$, trimethoprim $5 \mathrm{mg} / \mathrm{Lit}$, and $5 \%$ of defibrinated horse blood 5\%. Following 48 hours of microaerophilic incubation $\left(5 \% \mathrm{O}_{2}, 10 \% \mathrm{CO}_{2}, 85 \% \mathrm{~N}_{2}, 42^{\circ} \mathrm{C}\right)$, hemolytic, gray, 1-5 mm, circular, and aqueous colonies were selected and examined after gram staining. Gram-negative, spiral rod-shaped bacilli were isolated and were exposed to the oxidase and catalase tests. Bacteria with oxidase and catalase positive tests were transferred to a heart infusion broth containing sodium hippurate for the hippurate hydrolysis test and were incubated for $24-48 \mathrm{hr}$ at $42{ }^{\circ} \mathrm{C}$. Thereafter, $0.8 \mathrm{ml}$ of the medium was mixed with $0.2 \mathrm{ml}$ of the $\mathrm{FeCl}_{3}$ solution and stored for 30 minutes at the room temperature. The samples containing sediments were considered to contain C.jejuni (the hippurate in the medium was hydrolyzed and transformed into benzoic acid and glycine) and samples with no sediments were considered to contain other Campylobacter spp. (Henao et al., 2015). In this study, the standard C.jejuni strain ATCC 33560 was used as a positive control. For the molecular assay, the kits produced by the Iranian Nedaye Fan Company (Cat.NO: PR881613) were used to extract the DNA from the poultry carcasses samples. The PCR tests were also carried out using Jenet Bio kits (Cat.No: G-200o) in accordance with the kit instructions. The primers were selected from the relevant articles and were examined in the https://blast.ncbi.nlm.nih.gov/Blast.cgi.

Table-1: Primer Sequence used for detection of Campylobacter spp.

\begin{tabular}{|c|c|c|}
\hline Amplicon & Primer & Primer sequence $(5 /-3 /)$ \\
\hline $1062 \mathrm{bp}$ & Universal & $\begin{array}{l}\text { F: 5'-GGAGGC AGC AGT AGG GAA TA-3' } \\
\text { R: 5'-TGACGGGCGGTGAGTACAAG-3' }\end{array}$ \\
\hline 840 bp & $\begin{array}{l}\text { C.spp } \\
\text { (16srRNA) }\end{array}$ & $\begin{array}{l}\text { F:5'-GGAGGATGACACTTTTCGGAGCG-3' } \\
\text { R:5'-TCGCGGTATTGCGTCTCATTGTATATGC- }\end{array}$ \\
\hline $3^{\prime}$ & & \\
\hline 344 bp & $\begin{array}{l}\text { C.jejuni } \\
\text { (Hippo) }\end{array}$ & $\begin{array}{l}\text { F:5'-GACTTCGTGCAGATATGGATGCTT-3' } \\
\text { R:5'-GCTATAACTATCCGAAGAAGCCATCA-3' }\end{array}$ \\
\hline $500 \mathrm{bp}$ & $\begin{array}{l}\text { C.coli } \\
\text { (asp) }\end{array}$ & $\begin{array}{l}\text { F:5'-GGTATGATTTCTACAAAGCGAG-3' } \\
\text { R:5'-ATAAAAGACTATCGTCGCGTG-3' }\end{array}$ \\
\hline
\end{tabular}

In the molecular process, 4 primer pairs were used (Table 1); i) A 16s Universal primer for internal control (Persson \& Olsen, 2005), ii) A primer 16s rRNA for detection of all species of Campylobacter (Vanniasinkam et al., 1999), iii) A hipo primer (hippuricase gene) for detection of C.jejuni
(Persson \& Olsen, 2005), iv) A asp primer (aspartokinase gene) for detection of C.coli (Misawa et al., 2002).

The PCR tests were conducted on the DNAs, extracted from the poultry carcasses using the specific Campylobacter primer. In the samples when the presence of the Campylobacter DNA was conf irmed, each of the C.coli and C.jejuni species was subjected to molecular examinations using their genus-specific primers. The results from the PCR reactions were examined through an agarose gel (1.5\%) electrophoresis and ethidium bromide staining under ultraviolet radiation and the data were statistically analyzed in SPSS on the descriptive statistics level.

The presence of the specific DNA of Campylobacter in a molecular test was considered as the contamination of that sample with Campylobacter. The presence of specif ic C.coli and C.jejuni DNA in the molecular study was considered as the contamination of the sample with C.coli and C.jejuni.

\section{Results:}

According to the bacteriological assay results, 201 samples $(61.28 \%)$ of the 328 samples were infected with Campylobacter spp. The prevalence of C.jejuni and other Campylobacter spp. was 109 (33.23\%) and 92 (28.05\%), respectively. In the molecular assay (Fig.-1), $67.99 \%$ of the samples contained the Campylobacter (Table-2).

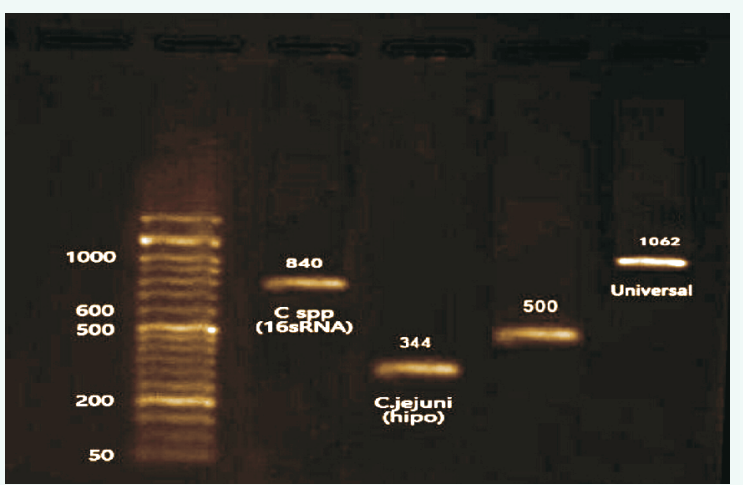

Figure-1: The result of the electrophoresis of the products of the PCR-based amplif ication of DNA extracted from the samples.

Table-2: Distribution of various Campylobacter spp.in the samples

\begin{tabular}{|c|c|c|}
\hline \multirow[t]{2}{*}{ Contamination } & \multicolumn{2}{|c|}{ Molecular Frequency } \\
\hline & Number & Percent \\
\hline Campylobacter jejuni & 116 & $35 \cdot 37$ \\
\hline Campylobacter coli & 65 & 19.82 \\
\hline Co-Contamination: C.jejuni \& C.coli & 29 & 8.84 \\
\hline Other Campylobacter species & 13 & 3.96 \\
\hline All Campylobacter contamination & 223 & 67.99 \\
\hline Non-contamination with Campylobacter & 105 & 32.01 \\
\hline Total & 328 & 100 \\
\hline
\end{tabular}

\section{Discussion:}

The results from this study revealed that the frequency of contamination with Campylobacter spp. in the poultry carcasses samples collected from the slaughterhouses of Jahrom was $61.28 \%$ and $67.99 \%$ from the bacteriological 
and molecular assays, respectively.

In other studies conducted in different cities of Iran, the frequency of meat contamination with Campylobacter was as follows: Isfahan $56.1 \%$ (Rahimi \& Tajbakhsh, 2008), Tehran 63.2\% (Dallal et al., 2010), Mashhad 76\%, and Shahr-e Kord $47 \%$ (Rahimi \& Ameri, 2011). These findings are parallel with the results obtained from the present study. The frequency of meat contamination with Campylobacter reported from the studies conducted elsewhere was as follows: Turkey 91.8\% (Yildirim et al., 2005), Korea 68.3\% (Han et al., 2007), Canada 62.4\% (Valdivieso-Garcia et al., 2007), and Japan 40-77\% (Sallam, 2007). These finding from mentioned researches are also resembling with our present results.

The molecular frequency of the C.jejuni was higher than C.coli (35.37\% vs. $19.82 \%)$ found in our study. These results have a consistency with the results of previous findings (Eyigor et al., 1999; Van Looveren et al., 2001). Therefore, the results from the present study may not comply with the results of the aforementioned studies. This statistical difference could be attributed to the lower prevalence of Campylobacter in the present study as compared to the other studies, the difference between the sampling techniques, the difference between the prevalence of Campylobacter in different seasons (with the lowest prevalence in spring and winter and the highest prevalence in autumn and summer), and the difference between the geographical regions. For instance, we carried out this research in the hot and arid regions.

In this study, the comparison between the molecular and bacteriological analyses revealed that 201 samples had both positive molecular and bacteriological performances. However, 22 samples had positive PCR results and negative bacteriological results. Their considerable difference between the diagnoses by the two methods is also worth mentioning. Majdani (2016) used the culture and PCR methods to study the prevalence of human diarrhea caused by C.jejuni and C.coli in Isfahan. He reported that of the 196 diarrhea cases, 18 were infected with Campylobacter following the PCR tests from which 18 cases 14 had the C. jejuni infection and 4 had an infection with C.coli. In the bacteriological examinations, 15 of the 196 diarrhea samples had positive Campylobacter results: 12 samples were infected with C.jejnui and the other 3 were infected with C.coli (Havaei et al., 2006; Majdani, 2016). The findings from present research and Fazli's research confirm the greater potential of the molecular method for diagnosing the contamination of foodstuff with Campylobacter spp. and other bacteria. As regards the research constraints, the small sample size was one of the limitations on this research, while sampling was carried out within a short period of time only in the low-prevalence seasons, viz. spring and winter.

Finally, the results from the present study indicate that
C.coli accounts for most of the poultry contamination in Jahrom-Iran. However, its prevalence is extremely lower than the results reported in the previous studies. The low prevalence of Campylobacter in the poultry meat in this part of Iran can be attributed to the application of the health principles in the chicken coops and slaughterhouses of this area.

\section{Acknowledgements:}

Jahrom University of Medical Sciences is highly acknowledged due to providing financial assistance to carry out this study.

\section{References:}

Adopted 28 September, Coral Gables, Fla. (2007): Analytical Utility of Campylobacter Methodologies. L. Food Protec., 70(1):241-250.

Allos, B.M. \& Blaser, M.J. (1995): Campylobacter jejuni and the expanding spectrum of related infections. Clin. Infect. Dis., 20(5):1092-1099.

Dabiri, A., Rouhi, S., Nouri, B. \& Zaboli, F. (2016): Assess the prevalence rate of Campylobacter genus and Campylobacter jejuni species in raw milk collected from the Amol City by Multiplex-Polymerase Chain Reaction. J. Fasa Univer. Med. Sci., 5(4):516-525.

Dallal, M.M.S., Doyle, M.P., Rezadehbashi, M., Dabiri, H., Sanaei, M., Modarresi, S., Bakhtiari, R., Sharifiy, K., Taremi, M., Zali, M.R. \& Yazadi, M.K.S. (2010): Prevalence and antimicrobial resistance profiles of Salmonella serotypes, Campylobacter and Yersinia spp. isolated from retail chicken and beef, Tehran, Iran. Food Control, 21(4):388-392.

Eyigor, A., Dawson, K.A., Langlois, B.E. \& Pickett, C.L. (1999): Detection of cytolethal distending toxin activity and cdt genes in Campylobacter spp. isolated from chicken carcasses. Appl. Environ. Microbiol., 65(4):1501-1505.

Fitzgerald, C. (2015): Campylobacter. Clin. Lab. Med. 35(2):289298.

Grennan, B., O'Sullivan, N.A., Fallon, R., Carroll, C., Smith, T., Glennon, M. \& Maher, M. (2001): PCR-ELISAs for the detection of Campylobacter jejuni and Campylobacter coli in poultry samples. Biotechniques, 30(3):602-610.

Han, K., Jang, S.S., Choo, E., Heu, S. \& Ryu, S. (2007): Prevalence, genetic diversity, and antibiotic resistance patterns of Campylobacter jejuni from retail raw chickens in Korea. Int. J. Food Microbiol., 114(1):50-59.

Havaei, S.A., Salehi, R., Bokaeina, M. \& Fazeli, S.A. (2006): Comparison of PCR and culture methods for diagnosis of enteropathogenic Campylobacter in fowl feces. Iranian Biomed. J., 10(1):47-50.

Henao, O.L., Jones, T.F., Vugia, D. \& Griffin, P.M. (2015): Foodborne diseases active surveillance network2 decades of achievements, 1996-2015. Emerg. Infect. Di., 21(9):1529.

Kaakoush, N.O., Castaño-Rodríguez, N., Mitchell, H.M. \& Man, S.M. (2015): Global epidemiology of Campylobacter infection. Clin. Microbiol. Rev., 28(3):687-720.

Majdani, R. (2016): Isolation of lytic bacteriophages against pathogenic Escherichia coli strains in poultry in the northwest of Iran. Arch. Razi Inst., 71(4):235-244.

Misawa, N., Kawashima, K., Kawamoto, H. \& Kondo, F. (2002): Development of a combined filtration-enrichment culture 
followed by a one-step duplex PCR technique for the rapid detection of Campylobacter jejuni and C.coli in human faecal samples.J.Med. Microbiol., 51(1):86-89.

Persson, S. \& Olsen, K.E. (2005): Multiplex PCR for identification of Campylobacter coli and Campylobacter jejuni from pure cultures and directly on stool samples.J. Med. Microbiol., 54(11):1043-1047.

Rahimi, E. \& Ameri, M. (2011): Antimicrobial resistance patterns of Campylobacter spp. isolated from raw chicken, turkey, quail, partridge, and ostrich meat in Iran. Food Control, 22(8):11651170.

Rahimi, E. \& Tajbakhsh, E. (2008): Prevalence of Campylobacter species in poultry meat in the Esfahan city, Iran. Bulgarian J. Vet. Med., $11(4): 257-262$.

Sahin, O., Morishita, T.Y. \& Zhang, Q. (2002): Campylobacter colonization in poultry: sources of infection and modes of transmission. Anim. Health Res. Rev., 3(2):95-105.

Sallam, K.I. (2007): Prevalence of Campylobacter in chicken and chicken by-products retailed in Sapporo area, Hokkaido, Japan. Food Control, 18(9):1113-1120.

Silva, J., Leite, D., Fernandes, M., Mena, C., Gibbs, P.A. \& Teixeira, P. (2011): Campylobacter spp. as a foodborne pathogen: a review. Front. Microbiol., 2:200.

Valdivieso-Garcia, A., Harris, K., Riche, E., Campbell, S., Jarvie, A., Popa, M., Deckert, A., Reid-Smith, R. \& Rahn, K. (2007): Novel Campylobacter isolation method using hydrophobic grid membrane filter and semisolid medium. L. Food prot., $70(2): 355-362$.
Van Looveren, M., Daube, G., De Zutter, L., Dumont, J.-M., Lammens, C., Wijdooghe, M., Vandamme, P., Jouret, M., Cornelis, M. \& Goossens, H. (2001): Antimicrobial susceptibilities of Campylobacter strains isolated from food animals in Belgium. I. Antimicrob. Chemother., 48(2):235240.

Vandeplas, S., Marcq, C., Dauphin, R.D., Beckers, Y., Thonart, P. \& Théwis, A. (2008): Contamination of poultry flocks by the human pathogen Campylobacter spp. and strategies to reduce its prevalence at the farm level. Biotechnologie, Agronomie, Société et Environnement (BASE), 12(3):317-334.

Vanniasinkam, T., Lanser, J. \& Barton, M. (1999): PCR for the detection of Campylobacter spp. in clinical specimens. Lett. Appl. Microbiol., 28(1):52-56.

Vicente, A., Barros, R., Florinda, A., Silva, A. \& Hanscheid, T. (2008): High rates of fluoroquinolone-resistant Campylobacter in Portugal-need for surveillance. Euro. Surveill., 13(6):3-4.

Yildirim, M., Istanbulluoðlu, E. \& Ayvali, B. (2005): Prevalence and antibiotic susceptibility of thermophilic Campylobacter species in broiler chickens. Turk. J. Vet. Anim. Sci., 29:655660. 